Poliana Moser, Vânia Regina Nicoletti, Stephan Drusch, Monika Brückner-Gühmann

\title{
Functional properties of chickpea protein- pectin interfacial complex in buriti oil emulsions and spray dried microcapsules
}

Journal article | Accepted manuscript (Postprint)

This version is available at https://doi.org/10.14279/depositonce-10491

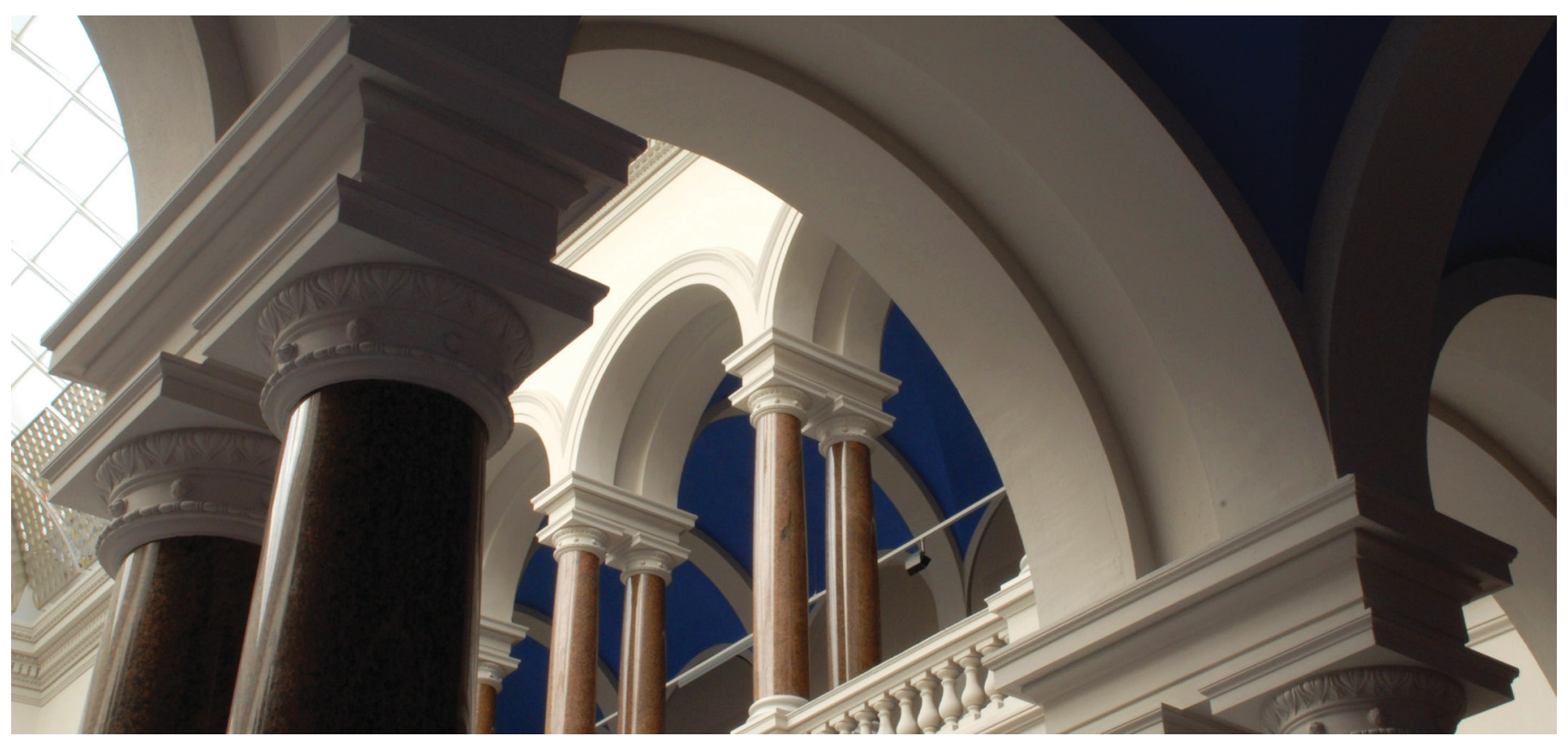

Moser, P., Nicoletti, V. R., Drusch, S., \& Brückner-Gühmann, M. (2020). Functional properties of chickpea protein-pectin interfacial complex in buriti oil emulsions and spray dried microcapsules. Food Hydrocolloids, 107, 105929. https://doi.org/10.1016/j.foodhyd.2020.105929 


\title{
Functional properties of chickpea protein-pectin interfacial complex in buriti oil emulsions and spray dried microcapsules
}

\author{
Poliana Moser a, , Vânia Regina Nicolettia , Stephan Drusch ${ }^{\mathrm{b}}$, Monika Brückner-Gühmann ${ }^{\mathrm{b}}$ \\ a Institute of Biosciences, Humanities and Exact Sciences, Department of Food Engineering \\ and Technology, São Paulo State University, Brazil \\ b Institute of Food Technology and Food Chemistry, Department of Food Technology and \\ Food Material Science, Technische Universität Berlin, Germany
}

${ }^{*}$ Corresponding author: Poliana Moser. Institute of Biosciences, Humanities and Exact Sciences, Department of Food Engineering and Technology, São Paulo State University, Cristóvão Colombo 2265, 15054-000 São José do Rio Preto, Brazil. E-mail address: polimoser@gmail.com

\begin{abstract}
The aim of the present study was to investigate the impact of chickpea protein (CP) alone or in the form of sequentially adsorbed chickpea protein and high methoxylated pectin (CPHMP) on the microencapsulation of buriti oil by spray drying. CP was extracted and characterized by its molecular weight distribution, zeta potential and solubility. The adsorption of $\mathrm{CP}$ and $\mathrm{CP}-\mathrm{HMP}$ complexes to the oil/water $(\mathrm{O} / \mathrm{W})$ interface was investigated by measurement of the interfacial tension. The intractions between the molecules at the $\mathrm{OM}$ interface were analyzed by interfacial shear rheology. Emulsions containing CP or CP-HMP were prepared at $\mathrm{pH} 3.5$, homogenized and spray dried at $180 / 70{ }^{\circ} \mathrm{C}$ and $210 / 90{ }^{\circ} \mathrm{C}$ (inlet/outlet) temperature. The oil droplet size distribution (ODS) of emulsions before and after spray drying, the encapsulation efficiency (EE) of microcapsules and their oxidative stability were evaluated. The interfacial tension of $\mathrm{CP}$ at the $\mathrm{O} / \mathrm{W}$ interface was not affected by pectin addition. However, interfacial shear rheology revealed strong interactions between CP-HMP complexes, maintaining the physical integrity of emulsion oil droplets during spray drying. On the other hand, interactions in the CP film were weaker and the droplets were affected by spray drying, suffering from an increase in size. The EE of CP-HMP microcapsules was higher than for CP microcapsules, which suggests a synergistic effect. The spray drying temperature had no effect on the EE. During six months of storage, a slight increase of the conjugated dienes content was observed for all microcapsules. However, the type of microcapsule and the temperature of spray drying had no effect on the development of lipid oxidation.
\end{abstract}

Keywords: chickpea protein; pectin; interfacial shear rheology; spray drying; microencapsulation; oxidative stability. 


\section{Introduction}

The fruits of the buriti palm tree (Mauritia flexuosa L.) have strong nutritional potential. The oil extracted from the buriti fruit is of great interest due to the high concentration of tocopherols $(1040 \mathrm{mg} / \mathrm{kg})$ and carotenoids $(687 \mathrm{mg} / \mathrm{kg})$, with $\beta$-carotene being the major compound (74\% of total carotenoids). Tocopherols are important antioxidants and present vitamin $E$ activity, while $\beta$-carotene is a pro-vitamin A compound (Freitas et al., 2018). Recently, Buriti oil has become a promising ingredient in food, chemical and cosmetic industries (Bovi et al., 2017).

Generally, microencapsulation is a possible approach to protect bioactive compounds and retard lipid oxidation, thus improving the oil stability (Böger et al., 2018). The microencapsulation process comprises the emulsification of the lipids in a solution of wall material followed by spray drying (Aberkane et al., 2014). In order to protect the oil droplets, surface active ingredients like proteins are required. During homogenization of oil and water, proteins adsorb to the interface, facilitating their disruption by lowering the interfacial tension and retarding the coalescence by forming a protective layer around the oil droplets (McClements, 2004). Physicochemical characteristics of proteins such as molecular size, surface hydrophobicity, charge, and molecular flexibility influence their emulsifying properties. Among these factors, surface hydrophobicity and surface charge are the most important molecular features that affect their functional attributes (Karaca et al., 2011).

During spray drying of emulsions, the core material is encapsulated in an amorphous matrix which reduces the mobility of the reactants and slows down the oxygen diffusion-rate (Drusch \& Diekmann, 2015). Factors such as drying air temperature and atomization can affect the characteristics of microcapsules. A sufficient drying temperature allows a rapid formation of the crust around the droplet, however, the level of the temperature is limited as too high temperatures cause "ballooning" of the drying droplet or heat damage to the dry product (Drusch \& Schwarz, 2006; Jafari, Assadpoor, He, \& Bhandari, 2008). In addition, stress caused by atomization can change the characteristics of the oil droplets, resulting in their disruption (Gharsallaoui et al., 2010). According to Drusch (2012), the preservation of the interfacial structure of droplets is essential to ensure a high encapsulation efficiency and thus the core material protection. Therefore, success of the spray drying is also reflected by the degree of preservation of the original emulsion structure, which can be evaluated by the droplet size distribution of the resuspended powder (Gharsallaoui et al., 2010).

Dairy proteins are commonly used as encapsulation agents, although in the last years, plant proteins have gained considerable interest. Among plant proteins, soy protein isolate (Moser et al., 2017; Ton et al., 2016), pea protein isolate (Gharsallaoui et al. 2012; Tamm et al. 2016) and cereal proteins (Rosenberg et al., 2018; Wang et al., 2011) have been used as matrix constituents. Chickpea protein (CP) was selected in this study for its high emulsifying potential (Ladjal-Ettoumi et al., 2016) and encapsulation ability (Karaca et al., 2013). The globular nature of CP enables the formation of thick and viscoelastic films around oil droplets, enhancing their stabilization during and after emulsification (Can Karaca, Low, \& 
Nickerson, 2015; Dickinson, 2009). However, under specific conditions, protein-stabilized emulsions still have some limitations, which must be overcome.

The use of polysaccharides to form complexes with protein is of large interest because it increases the physical stability of the emulsion via electrostatic and steric effects, increases the viscosity of the aqueous phase, modifies the interfacial rheological properties and stabilizes interfacial layers (Dickinson, 2011; Gharsallaoui et al., 2012; Serfert et al., 2013). The formation of the protein-polysaccharide complexes can be realized either by sequential adsorption of the protein and pectin using the layer-by-layer technique or by simultaneous adsorption of protein and pectin from a mixture of both substances resulting in a mixed interfacial film (Ganzevles et al., 2007). Using the layer-by-layer technique, a polysaccharide is added to a previously established protein-stabilized interface (Jourdain et al., 2009) and a sequential adsorption takes place. The complex formation occurs by electrostatic interaction between proteins and anionic polysaccharides at a $\mathrm{pH}$ below the isoelectric point of the protein (Serfert et al., 2013).

Pectin as an anionic polysaccharide is classified by the degree of esterification of its galacturonic acid backbone. In high methoxylated pectin (HMP) half or more of the carboxylic groups are esterified, in low methoxylated pectin (LMP) less than a half of the carboxylic groups are esterified (Freitas et al., 2017). The ability to protect encapsulated lipid against oxidation has already been shown for pea protein-pectin and whey proteinpectin systems (Aberkane et al., 2014; Gharsallaoui et al., 2010; Serfert et al., 2013). However, interfacial properties of chickpea protein-based interfacial complexes have not been reported before. Moreover, the mechanical properties of interfacial complexes, which means in detail their ability to form a viscoelastic interfacial layer, are detrimental for their performance during emulsification and spray drying processes. In consequence, the correlation of interfacial rheology to emulsification properties is of utmost importance.

Due to the presence of calcium in CP, only HMP can be used to form complexes with this protein. The use of small amount of LMP resulted in a highly viscous emulsion that was no longer suitable for spray drying. At present, no data on spray dried emulsions containing CP-HMP are available in literature. The current study therefore aims to estimate the impact of chickpea protein alone or in combination with high methoxylated pectin on the microencapsulation of buriti oil by spray drying. It is hypothesized that electrostatic complexes will be formed between chickpea protein and pectin resulting in viscoelastic films, microcapsules with high encapsulation efficiency and improved stability. The CP protein was extracted and physicochemically characterized. The adsorption of CP and CP-HMP complexes at the $\mathrm{O} N$ interface, the formation of an interfacial film and its stability were investigated. The success of microencapsulation was monitored by changes in the oil droplet size of the reconstituted emulsions before and after spray drying, the microencapsulation efficiency (amount of extractable oil) as well as the oxidative stability (formation of conjugated dienes). 


\section{Material and methods}

\subsection{Materials}

Refined buriti oil (Rain Forest RF3810, Beraca, Ananindeua, Brazil) was used as a model substance. According to the manufacturer's specification, the oil contained $74.7 \%$ oleic acid and $17.7 \%$ palmitic acid. It was kept at $-35^{\circ} \mathrm{C}$ until use. Chickpea protein (CP) was extracted from Kabuli chickpea (Global Foods Trading $\mathrm{GmbH}$, Germany) and used as emulsifier. High methoxylated pectin (HMP) (Herbstreith \& Fox, Germany), with a degree of methoxylation of $71.4 \%$ and galacturonan content of $75.6 \%$, was used as stabilizer. Glucose syrup (GS) (DE 38, C*Dry 01934) and Medium chain triglyceride oil (MCT oil, CremerCOOR MCT 60/40) were purchased from Cargill (Germany) and Cremer Oleo (Germany), respectively. All chemicals used were of analytical grade.

\subsection{Chickpea protein extraction and characterization}

Chickpea protein was extracted following the methodology used by Papalamprou, Doxastakis and Kiosseoglou (2010), with modifications. In brief, the seeds of chickpea were crushed and mixed with distilled water at a $1: 3$ ratio (w/v), adjusted to $\mathrm{pH} 8$ using $\mathrm{NaOH}$, and stirred (500 rpm, $45 \mathrm{~min}$ ) at room temperature. The suspension was centrifuged $\left(10.000 \times \mathrm{g}, 60 \mathrm{~min}, 20^{\circ} \mathrm{C}\right)$, the top fat layer was removed using a pipette, and the supernatant was freeze-dried. The protein composition was determined following the official methods of the AOAC (2016). The CP contained $48.7 \pm 0.2 \mathrm{wt} \%$ protein, $5.2 \pm 0.0 \mathrm{wt} \%$ fat, $4.8 \pm 0.3 \mathrm{wt} \%$ moisture, $6.7 \pm 0.0 \mathrm{wt} \%$ ash, $13.6 \pm 0.5 \mathrm{wt} \%$ fiber and $21.0 \pm 0.2 \mathrm{wt} \%$ carbohydrates.

The molecular weight distribution of the protein was analyzed by tris-tricine SDS-PAGE and size exclusion chromatography (SEC). SDS-PAGE was carried out according to the method described by Tamm et al. (2015), under reducing and non-reducing conditions. Samples were diluted with tris-tricine buffer (cat\#161-0744 Bio-Rad) and, for reducing condition, $1 \mathrm{M}$ DL-dithiothreitol (DTT) solution (Sigma Aldrich) was used. The samples were heated $\left(90^{\circ} \mathrm{C}\right.$, $5 \mathrm{~min}$ ) and loaded on a $16.5 \%$ tris-tricine gel (cat\# 345-0065, Bio-Rad). A commercial mixture of peptides, ranging from 10 to $170 \mathrm{kDa}$, was used as marker (cat\# 26616, Thermo Scientific). SEC was carried out on HPLC ÄKTAbasic ${ }^{T M} 10$ (Amersham Biosciences, Sweden), according to Brückner-Gühmann et al. (2018). The analysis was performed using phosphate buffer at $\mathrm{pH} 7$. The molecular weight of the peaks in the chromatogram of the $\mathrm{CP}$ was calculated using the following gel filtration calibration kits with low and high molecular weight standards (GE healthcare $\mathrm{GmbH}$, Germany): ferritin (440 kDa), aldolase (158 kDa), conalbumin (75 kDa), ovalbumin (44 kDa), carbonic anhydrase (29 kDa), ribonuclease (13.7 $\mathrm{kDa})$, and aprotinin (6.5 kDa).

The zeta potential and solubility of $\mathrm{CP}$ were evaluated in the $\mathrm{pH}$ range from 3 to 9 and from 2 to 10 , respectively. The zeta potential was analyzed by electrophoretic light scattering (Zetasizer Nano-ZS, Malvern Instruments $\mathrm{GmbH}$, Germany). The protein was dissolved 200 -fold in water, the $\mathrm{pH}$ adjusted, and the solution was measured using disposable capillary 
cells (DTS1061). The coefficient of variation related to the methodology was determined based on six individual measurements. The measurement of the zeta potential showed a coefficient of variation of 0.14 . To evaluate the solubility, the protein was solubilized in water $1: 10(\mathrm{w} / \mathrm{w})$, the $\mathrm{pH}$ was adjusted, the solutions were stirred (300 rpm, $60 \mathrm{~min})$ and centrifuged (10.000 rpm, $10 \mathrm{~min})$. The protein content in the supernatant was determined and the solubility calculated.

\subsection{Interfacial tension and shear rheology of CP and CP-HMP}

The influence of $\mathrm{CP}$ and CP-HMP complexes on the interfacial tension at the oil/waterinterface was determined using an automated drop tensiometer (OCA20, Dataphysics $\mathrm{GmbH}$, Germany). The oil phase employed was MCT oil, previously treated with activated magnesium silicate (Florisil 60 - 100 mesh, WWR, Germany) to remove interfacial active compounds. Solutions of CP (0.1 wt \%) and CP-HMP (0.1-0.03 wt \%, maintaining the same proportion of protein-pectin evaluated in this study) were prepared in acetate buffer at $\mathrm{pH}$ 3.5. A drop of solution was created using a needle into a cuvette of MCT oil. Subsequently, the interfacial tension was measured for $30 \mathrm{~min}$.

The interfacial shear rheology was investigated according to Tamm and Drusch (2017). The time sweep, amplitude sweep, and frequency sweep were carried out on shear rheometer MCR 301 or MCR 102 (Anton Paar GmbH, Ostfildern, Germany) equipped with a biconical disk geometry. Time sweep was performed for ten hours with a constant deformation of $0.1 \%$ at a frequency of $0.1 \mathrm{~Hz}$. Amplitude sweep was performed at a deformation between 0.001 to $100 \%$ at a frequency of $0.1 \mathrm{~Hz}$. Frequency sweep was performed from 1 to 0.0015 $\mathrm{Hz}$, with constant deformation of $0.001 \%$. All experiments were performed at $25^{\circ} \mathrm{C}$ in duplicate. The coefficient of variation related to the methodology was determined based on measurement of five individual plant proteins. The IRS method shows a coefficient of variation of 0.17 .

\subsection{Preparation of emulsions}

The emulsions were prepared using sequential adsorption, the layer-by-layer technique, according to the method described by Serfert et al. (2013), with modifications. The emulsion containing only CP was prepared using $1.6 \mathrm{wt} \% \mathrm{CP}, 10.0 \mathrm{wt} \%$ buriti oil, and $33.4 \mathrm{wt} \% \mathrm{GS}$ (dry matter $45.0 \mathrm{wt} \%$ ), whereas the emulsion resulting from sequential adsorption of CP and HMP additionally contained $0.5 \mathrm{wt} \%$ HMP (dry matter $45.5 \mathrm{wt} \%$ ). The GS was chosen as drying agent because it can be used at high concentrations without appreciably affecting emulsion stability and rheology (Klinkesorn et al., 2006).

To prepare the primary emulsion, firstly CP and HMP were dissolved using acetate buffer at $\mathrm{pH} 3.5$, mixed for 2 hours, and hydrated overnight. The glucose syrup was dissolved with buffer or buffer/HMP by magnetic stirring until complete dissolution. Then, the emulsion was prepared by shear homogenization at $21.000 \mathrm{rpm}$ for $90 \mathrm{~s}$ (Ultra-Turrax T25 basic, IKA, Germany) of buriti oil into CP solution, followed by high-pressure homogenizer at $300 \pm 50$ bar (Panda Plus, Niro Soavi, Germany), applying 2 passes. This emulsion was subsequently 
diluted with GS or GS/HMP solutions to obtain single layer or sequentially adsorbed CPHMP emulsions, respectively, and homogenized at $200 \pm 50$ bar, applying 1 pass. The zeta potential of the single layer and the sequentially adsorbed CP-HMP emulsions was evaluated to ensure that the first protein layer was surrounded by pectin. The zeta potential was determined in triplicate.

\subsection{Microencapsulation by spray drying}

Spray drying of emulsions was carried out on a Mobile minor (Niro A/S, Copenhagen, Denmark) at $180 / 70{ }^{\circ} \mathrm{C}$ and $210 / 90{ }^{\circ} \mathrm{C}$ inlet/outlet temperature, using two-fluid nozzle, operating at 2 bar. To evaluate the impact of the spray drying process on oil droplet size distribution (ODS), reconstituted emulsions were analyzed and compared with fresh emulsions. The emulsions were reconstituted by dissolving the powdered microcapsules in acetate buffer by slow magnetic stirring during $15 \mathrm{~min}$. The ODS was determined by laser diffraction (Horiba LA-950, Retsch Technology $\mathrm{GmbH}$, Haan, Germany). A drop of rehydrated emulsion was suspended in distilled water. The particle size was calculated using a refractive index of 1.45 for buriti oil and 1.33 for water. Results of the volume distribution are presented as the $10^{\text {th }}, 50^{\text {th }}$ and $90^{\text {th }}$ percentiles of the oil droplets. The spray drying was performed once for each condition. Error bars result from replicates in analytical tests.

\subsection{Characterization and stability of microcapsules}

The encapsulation efficiency can be measured by extracting the non-encapsulated oil, which is mainly located at the particle surface or in interstitial voids located close to the surface (Drusch \& Berg, 2008). The extractable oil was determinate gravimetrically according to the method described by Westergaard (2004). The powder was weighed (10 g) into a screw capped flask, petrol ether was added $(50 \mathrm{~mL})$, and the dispersion was mixed slowly for 15 min. The dispersion was filtered and the filtrate was evaporated. Then, the residual oil was weighed and the amount of extractable oil was calculated. The total oil of the powder was assumed to be equal to the initial oil in the emulsion (Tonon et al., 2011). The encapsulation efficiency (EE) was calculated as follows:

$\mathrm{EE}=\left(\frac{\mathrm{TO}-\mathrm{EO}}{\mathrm{TO}}\right) \times 100$

where TO is the total oil content and EO is the extractable oil.

The stability of buriti oil was monitored by analyses of conjugated dienes. The microcapsules were stored in duplicate, in the dark, at 33\% relative humidity for 6 months. The extraction of oil was carried out following the method described by Morales-Medina et al. (2016). The powder was dissolved with water, blended with 2-propanol/isooctane $(1: 1, \mathrm{v} / \mathrm{v})$, stirred (2 $\mathrm{min})$ and centrifuged $(670 \times \mathrm{g}, 2 \mathrm{~min})$. Conjugated dienes were determined by spectrophotometry (Cecil, CE 1020) at $234 \mathrm{~nm}$. The results were expressed as $\mathrm{mmol} / \mathrm{kg}$ oil using a molar coefficient of 26000 for methyl linoleate hydroperoxides (Drusch, Serfert, \& Schwarz, 2006). 


\subsection{Statistical analysis}

The statistical significance between both samples in terms of interfacial shear rheological data (G' ${ }_{10 \mathrm{~h}}$ and $\mathrm{G}^{\prime}{ }_{10 \mathrm{~h}}$ ) and the zeta potential of the CP or HMP solution as well as single layer or the sequentially adsorbed CP-HMP emulsions was evaluated by means of an ANOVA ( $p<0.05)$ using SPSS Statistics Version 26 (Spss Inc., Chicago, USA).

Statistical significance of the time-dependent development of conjugated dienes was evaluated by Kruskal-Wallis test. Dunn-Bonferroni test was applied to determine the differences between the individual samples $(p<0.05)$ (SPSS Statistics Version 26, SPSS Inc., Chicago, USA).

\section{Results and discussion}

\subsection{Physicochemical characterization of chickpea protein}

\subsubsection{Molecular weight distribution of CP}

The molecular weight distribution of $\mathrm{CP}$ was characterized by SDS-PAGE and size exclusion chromatography (SEC). The results of the SDS-PAGE under reducing and non-reducing conditions are presented in Fig. 1. In general, CP contains two major protein fractions, globulins $(60-80 \%)$ and albumins $(15-25 \%)$. The globulin is constituted of legumin and vicilin (Clemente et al., 2000). In SDS-PAGE, bands are detected at approx. 60, 37 and $25 \mathrm{kDa}$, which may be attributed to legumin, and its acidic and basic subunit, respectively (BarEl Dadon et al., 2013; Ladjal-Ettoumi et al., 2016). Under reducing conditions, bands at 37 and $25 \mathrm{kDa}$ intensified. According to Tamm et al. (2016), these intensifications is due to the cleavage of inter- and intramolecular disulfide bonds, through which the legumin $(60 \mathrm{kDa})$ is disrupted into acid and basic fragments. The band at $72 \mathrm{kDa}$ corresponds to convicilin and the band around $50 \mathrm{kDa}$ may be attributed to vicilin (Ladjal-Ettoumi et al., 2016). Bands at $15 \mathrm{kDa}$ correspond to vicilin subunits (Chang et al., 2012). In the chickpea protein, albumins are present in less quantity than globular proteins. The band at $27 \mathrm{kDa}$ corresponds to albumin PA2, whereas the band at 92 kDa may be attributed to the presence of lipoxygenase

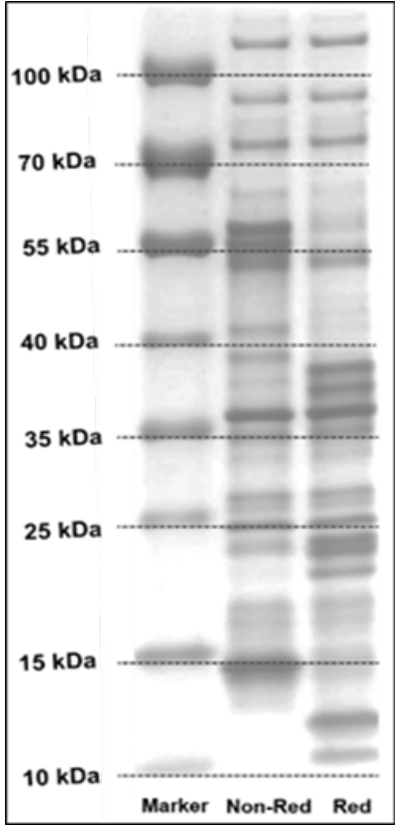

Fig. 1 Molecular weight distribution of the chickpea protein analyzed by SDS-PAGE, under non-reducing (Non-Red) and reducing (Red) conditions. (Clemente et al., 2000).

Since SDS-PAGE does not visualize the quaternary structure of proteins, CP was examined by SEC (Fig. 2). The first and the second peaks, with a molecular weight (MW) higher than $440 \mathrm{kDa}$, are probably composed of protein aggregates (Sanchéz-Vioque et al., 1999). The hexameric form of legumin eluted in peak A (area of 10.3\%), with a MW of $336 \mathrm{kDa}$. Peak 
$\mathrm{B}$ (area of $4.1 \%$ ), MW of $133 \mathrm{kDa}$, corresponds to the trimeric form of vicilin (Karaca et al., 2011). The peaks $C$ (area of $4.9 \%$ and MW of $62 \mathrm{kDa}$ ), D (area of $4.7 \%$ and MW of $27 \mathrm{kDa}$ ), and $E$ (area of $7.3 \%$ and $\mathrm{MW}$ of $15 \mathrm{kDa}$ ), which had already been observed by SDS-PAGE, correspond to legumin, albumin and fragments of vicilin, respectively. In addition, protein structures smaller than $10 \mathrm{kDa}$ were observed.

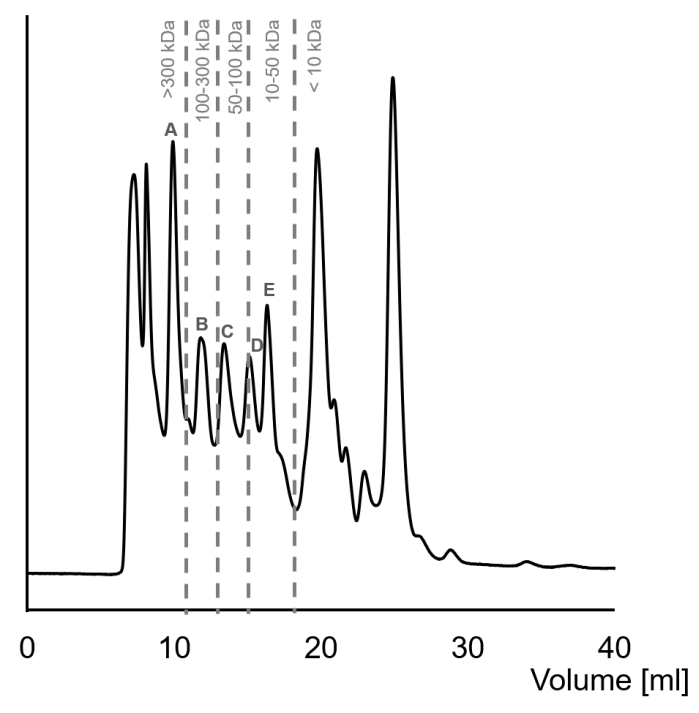

(a)

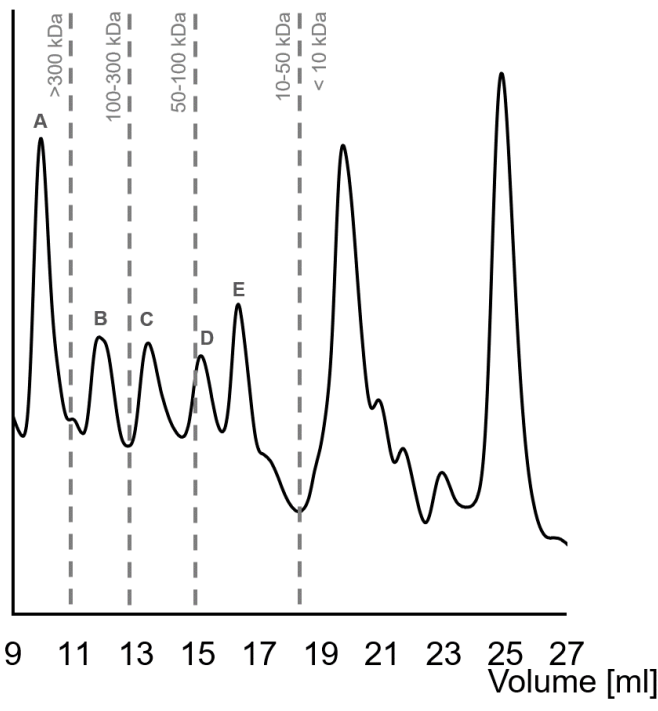

(b)

Fig. 2 Molecular weight distribution of the chickpea protein analyzed by size exclusion chromatography (SEC): (a) Original curve (b) zoomed curve.

\subsubsection{Zeta potential and solubility of CP}

Surface charge is an important characteristic of proteins, which determines their functional properties. The variation of $\mathrm{pH}$ resulted in different $\zeta$-potentials, with $32.5 \pm 1.8 \mathrm{mV}$ being the highest value at $\mathrm{pH} 3$ and $-35.6 \pm 2.0 \mathrm{mV}$ the lowest at $\mathrm{pH}$ 9. The changes are a result of the protonation or deprotonation of carboxylic groups and amino groups of the protein depending on the $\mathrm{pH}$ of the continuous phase (Ladjal-Ettoumi et al., 2016). At pH 5, the $\zeta-$ potential was zero, which is close to the isoelectric point ( $\mathrm{pl}$ ) of the protein. A pl between $\mathrm{pH}$ 4.5 and 5 was reported by Karaca et al. (2011) and Ladjal-Ettoumi et al. (2016). Around their pl, proteins tend to aggregate, which is attributed to weak electrostatic repulsion between the globular protein molecules as well as hydrophobic protein- protein interactions (Jones \& Mcclements, 2011; Madadlou et al., 2018). At the pl, the protein-water interaction is minimal, resulting in a low protein solubility and an increased tendency to precipitate (Gehring et al., 2011).

The solubility of proteins depends of the equilibrium between protein-solvent (hydrophilic) and the protein-protein (hydrophobic) interactions (Ladjal-Ettoumi et al., 2016). This interaction is a function of the surface charge, which is correlated to the $\mathrm{pH}$. The CP protein presented the lowest solubility $(38 \%)$ at $\mathrm{pH} 5$, increasing gradually below and above this $\mathrm{pH}$. At $\mathrm{pH} 2$ and 3, the solubility was more than $92 \%$ and at $\mathrm{pH}$ in the range of 8 to 10 solubility was $99 \%$. 


\subsection{Interfacial tension and shear rheology of CP and CP-HMP}

The ability of a protein to adsorb to an oil/water-interface and decrease the interfacial tension is an essential requirement to emulsification (Tamm \& Drusch 2017). When pectin has sufficient negative charge, it interacts electrostatically with protein. The interfacial properties were analyzed of CP alone or as a CP-HMP mixture. The interfacial tension was determined by drop tensiometry. The formation of intermolecular interactions between adsorbed molecules at the interface was analyzed by interfacial shear rheology. As stated by Dickinson (2011), measurements at macroscopic interfaces are not able to reflect the complex conditions that occur during emulsification, atomization and microencapsulation processes. Nevertheless, the results obtained by these methods provide important information for the performance and stability in food emulsions. Therefore, we propose that the results obtained for interfacial properties of simultaneously adsorbed CP-HMP complexes can help to understand mechanisms that are involved in sequential adsorption.

The CP solution presented an interfacial tension of $19.8 \pm 1.1 \mathrm{mN} / \mathrm{m}$ at the oil/water interface and was not affected by pectin addition (CP-HMP $=18.8 \pm 0.5 \mathrm{mN} / \mathrm{m}$ ), both after $30 \mathrm{~min}$ of droplet aging. Serfert et al. (2013) also observed that low and high methoxylated pectin did not influence the interfacial tension of $\beta$-lactoglobulin. In chickpea protein, the vicilin was found to have higher adsorption abilities at the interfacial layer than legumin, due to the lower molecular weight and higher flexibility (Dagorn-Scaviner, Gueguen \& Lefebvre, 1987). In contrast to vicilin, convicilin showed poor adsorption abilities (Xiong et al., 2018). The globulins are less soluble compared to albumins and possess higher surface hydrophobicity, being more effective in the reduction of the interfacial tension (Papalamprou et al., 2010).

The interfacial shear rheology experiments give insight into the mechanical strength of the intermolecular interactions between adsorbed molecules at the interface (Tamm and Drusch 2017). The interfacial shear rheology of CP and CP-HMP complexes at the MCT oil/water interface was evaluated by time sweep, amplitude sweep and frequency sweep. The timedependant film formation was evaluated by application of small deformation and frequency over a time period of 10 hours. As a result, the interfacial storage modulus $\left(G_{i}{ }^{\prime}\right)$ was found to increase over time for CP and CP-HMP complexes (Fig. 3). In general, as stated by Jung, Gunes, and Mezzenga (2010), a stabilization mechanism provided by globular proteins at the interface comprises the formation of a strong viscoelastic layer, which is attributed to the formation of a physical gel-like network held by covalent bonds. Madadlou et al. (2020) observed a time dependant polimerization between $\beta$-lactoglobulin molecules adsorbed to an air/water-interface. The polymerization results from the exposure of free sulfhydryl groups in the course of adsorption, unfolding and film formation at the interface. The interactions between the protein molecules were related to the formation of disulphide crosslinks. Dickinson and Matsumura (1991) evaluated $\beta$-lactoglobulin adsorption at the oil/water interface and observed that intermolecular disulphide bonds were formed. 


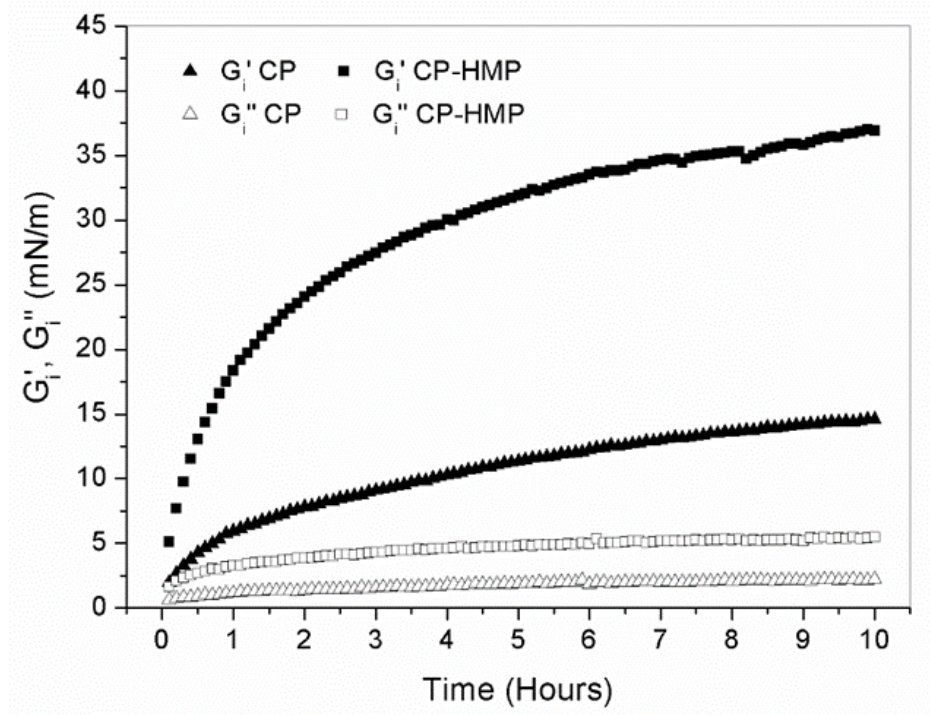

Fig. 3 Shear time sweeps of CP and CP-HMP solutions at the oil/water interface.

The interactions within the molecules at the interface were stronger (significantly higher $\mathrm{G}_{10 \mathrm{~h}}$, Table 1) between the oppositely charged CP-HMP than between the CP molecules alone. The oppositely charged polymers resulted in a strong interfacial electrostatic attraction with a pronounced effect on the interfacial complex formation, pointing to interfacial ordering (Krägel \& Derkatch, 2010). It was already observed for an air/water interface by Piazza et al. (2009) that pectin increased the $\mathrm{G}_{i}^{\prime}$ of soy protein, attributing the stabilizing effect of the polysaccharide to the complex formation. Dickinson and Euston (1991) observed that propylene glycol alginate (PGA) addition in the caseinate adsorbed layer at the oil/water interface resulted in the formation of a more structured film. This behavior was attributed to protein/PGA complexation arising from strong electrostatic interaction between the anionic polysaccharide and the protein below its isoelectric $\mathrm{pH}$. Dickinson, Semenova, Antipova, \& Pelan (1998) observed that high methoxylated pectin leads to an increase in the casein surface viscoelasticity, attributing this behavior to attractive protein-polysaccharide interaction at the oil/water interface.

Table 1 Interfacial shear rheological data (G'10h and G"10h) and zeta potential of single layer and the sequentially adsorbed CP-HMP emulsions

\begin{tabular}{|c|c|c|c|}
\hline Sample & $\begin{array}{c}\mathbf{G}^{\prime} 10 \mathrm{~h} \\
{[\mathrm{mN} / \mathrm{m}]}\end{array}$ & $\begin{array}{c}\text { G"' } 10 \mathrm{~h} \\
{[\mathrm{mN} / \mathrm{m}]}\end{array}$ & $\begin{array}{c}\zeta \text {-potential of emulsions } \\
{[\mathrm{mV}]}\end{array}$ \\
\hline CP emulsion & $16.9 \pm 2.7^{a}$ & $2.5 \pm 0.4^{a}$ & $32.2 \pm 1.4^{a}$ \\
\hline CP-HMP emulsion & $37.2 \pm 5.8^{b}$ & $5.5 \pm 0.9^{b}$ & $-4.6 \pm 0.9^{b}$ \\
\hline
\end{tabular}

Different letters in a column indicate significant differences at $p<0.05$

Amplitude sweeps were applied to the interfacial layers of CP and CP-HMP complexes to investigate the network properties ( $G_{i}^{\prime}$ and $G_{i}$ ') as a function of strain. CP-HMP resulted in higher $\mathrm{G}_{i}^{\prime}$ than $\mathrm{CP}$, resulting in stronger interfacial films (Fig. 4). The CP-HMP presented intersection point of $\mathrm{G}_{i}{ }^{\prime}$ and $\mathrm{G}_{\mathrm{i}}{ }^{\prime \prime}$ at $10 \%$ of deformation. In contrast to the CP-HMP, the CP 
did not show a linear viscoelastic behavior at low deformation, pointing at a weaker film which was influenced at low frequencies. Tamm and Drusch (2017) evaluated various protein/peptide-pectin combinations and also observed a film breakdown at a deformation of approximately $10 \%$. In the shear frequency sweeps $\mathrm{G}_{i}{ }^{\prime}$ was higher than $\mathrm{G}_{i}$ ' for $\mathrm{CP}$ and CP-HMP solutions, without crossover of the modulus (data not shown). No frequency dependence was observed for both systems.

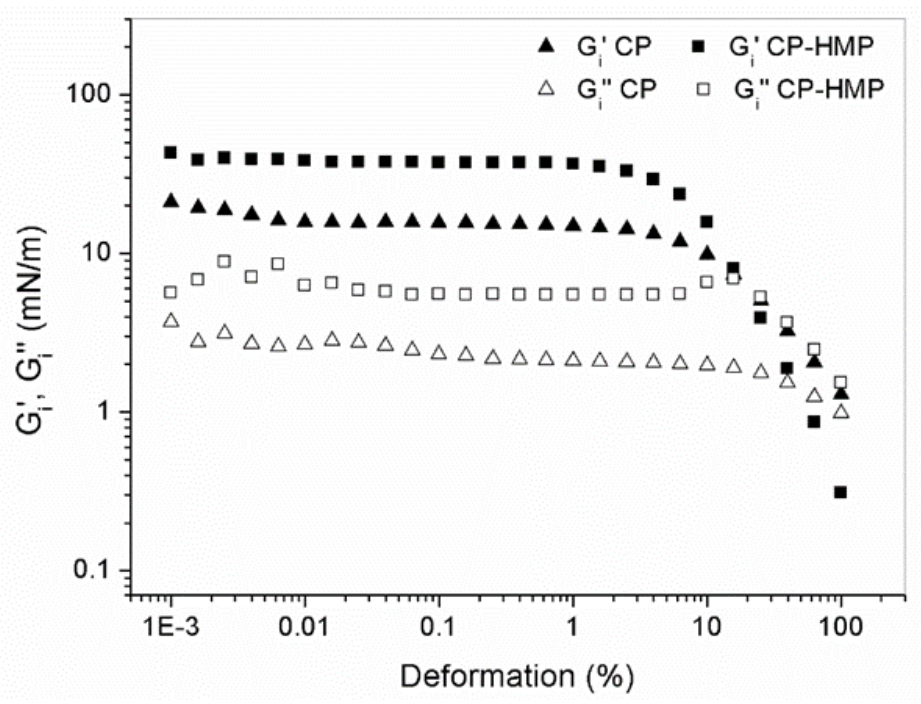

Fig. 4 Shear amplitude sweeps of CP and CP-HMP solutions at the oil/water interface.

\subsection{Characterization of emulsions}

Based on $\zeta$-potential results of the CP solution discussed in section 3.1.2, the $\mathrm{pH} 3.5$ was selected to produce the emulsions. At $\mathrm{pH} 3.5$, the CP solution presented a charge of $22.5 \pm$ $1.0 \mathrm{mV}$, whereas the HMP solution had a negative $\zeta$-potential of $-11.9 \pm 1.0 \mathrm{mV}$. The $\zeta-$ potential of the CP solution was significantly different from the CP-HMP solution. These charges suggest that an electrostatic binding between cationic amino groups on the CP and anionic carboxyl groups on the HMP surface is possible. To confirm that the pectin concentration used was sufficient to form complexes with the protein, the $\zeta$-potential of the single layer emulsion and the sequentially adsorbed CP-HMP emulsions was evaluated. The CP emulsion showed a positive charge, whereas CP-HMP emulsion was negatively charged, Table 1 . The negative charge can be attributed to the saturation of the protein interface with pectin (Serfert et al., 2013).

\subsection{Microencapsulation by spray drying}

The emulsions formulated with CP or CP-HMP were spray dried at two inlet air temperatures with one single drying for each condition. The ODS of emulsions before (fresh emulsion) and after (reconstituted emulsion) spray drying and the encapsulation efficiency of the microcapsules are presented in Table 2. The ODS of CP and CP-HMP fresh emulsions were smaller than $1.5 \mu \mathrm{m}$ in all percentiles, although CP resulted in larger ODS than CP-HMP. 
Table 2 Oil droplet size in fresh and reconstituted emulsions after spray drying formulated with CP or $C P-H M P$ and encapsulation efficiency (EE) of microcapsules

\begin{tabular}{|c|c|c|c|c|c|}
\hline \multirow[t]{2}{*}{ Sample } & \multicolumn{3}{|c|}{ Percentile of oil droplet size $(\mu \mathrm{m})$} & \multirow[t]{2}{*}{ Span } & \multirow[t]{2}{*}{ EE (\%) } \\
\hline & $10^{\text {th }}$ & $50^{\text {th }}$ & $90^{\text {th }}$ & & \\
\hline & \multicolumn{4}{|c|}{ Fresh emulsions (before spray drying) } & \\
\hline $\mathrm{CP}$ & $0.31 \pm 0.01$ & $0.61 \pm 0.00$ & $1.26 \pm 0.02$ & 1.58 & n.d. \\
\hline CP-HMP & $0.29 \pm 0.01$ & $0.52 \pm 0.01$ & $0.88 \pm 0.01$ & 1.11 & n.d. \\
\hline \multicolumn{6}{|c|}{ Reconstituted emulsions (after spray drying) } \\
\hline $\mathrm{CP} 180 / 70{ }^{\circ} \mathrm{C}$ & $0.33 \pm 0.02$ & $0.88 \pm 0.07$ & $3.52 \pm 0.21$ & 3.55 & $86.7 \pm 1.6$ \\
\hline $\mathrm{CP} 210 / 90{ }^{\circ} \mathrm{C}$ & $0.39 \pm 0.02$ & $1.03 \pm 0.04$ & $3.12 \pm 0.12$ & 2.82 & $86.8 \pm 1.5$ \\
\hline CP-HMP $180 / 70{ }^{\circ} \mathrm{C}$ & $0.30 \pm 0.00$ & $0.55 \pm 0.00$ & $0.97 \pm 0.00$ & 1.21 & $98.0 \pm 0.3$ \\
\hline CP-HMP $210 / 90{ }^{\circ} \mathrm{C}$ & $0.30 \pm 0.00$ & $0.55 \pm 0.00$ & $1.00 \pm 0.01$ & 1.28 & $98.4 \pm 0.2$ \\
\hline
\end{tabular}

When comparing the ODS of fresh and reconstituted emulsions, an increase in the droplet size was observed for CP. On the other hand, for CP-HMP, there was no increase in the droplet size of fresh and reconstituted emulsions. Similar behavior was reported by Gharsallaoui et al. (2010), using pea protein and pea protein-pectin. They observed an increase in the ODS for reconstituted single layer emulsions, while bilayer emulsions were less affected by spray drying. According to the authors, different physicochemical processes may occur during spray drying, that promote oil droplet instability using protein, including interfacial film structure changes and adsorbed protein conformational modifications. The increase in droplet size is attributed to damage of the emulsion droplets during the atomization (Drusch, 2007). Probably, the stronger film formed by CP-HMP complexes helped to preserve the interface integrity of the droplets during spray drying. In the fresh CPHMP emulsion, the span of the spray dried droplet size distribution was narrower than in the CP emulsion, which induces a better overall drying performance (Walzel, 2010).

In the reconstituted CP emulsions, the spray drying at higher temperature resulted in an increase in the ODS for $10^{\text {th }}$ and $50^{\text {th }}$ percentiles. In contrast, in CP-HMP the temperature did not affect the ODS. In addition to interfacial film stability, during drying process, high air temperature may lead to ballooning (Drusch \& Schwarz, 2006), increasing the droplet size. The ballooning occurs due to fast evaporation of water from the particle surface, which develops a crust and blocks the transport of water to the particle surface. Since no evaporation occurs any longer, the particle heats up to the temperature of the air and the steam formation inside the particle leads to its inflation (Drusch \& Diekmann, 2015). In the thin carrier matrix shell oil droplets are in close contact and oil drop coalescence is facilitated.

According to Aberkane et al. (2014), the smaller oil droplets are more stable, while the increase of size makes the droplets more sensitive to disruption during atomization, resulting in increased surface oil on the powder particles and, consequently, lower encapsulation efficiency. As a consequence of the change in oil droplet size, in the present study 
encapsulation efficiency (EE) of CP-HMP microcapsules was higher than of CP, which demonstrates that pectin supports chickpea protein resulting in improved oil encapsulation during spray drying. In contrast, spray drying temperature did not affect the encapsulation efficiency of microcapsules.

\subsection{Lipid oxidation of buriti oil}

Normally the lipid oxidation is monitored by the hydroperoxide content which is determined by a colorimetric method (International Dairy Federation, 1991). However, as buriti oil has an orange-red color, it was not possible to use this method, thus, oxidation was monitored by the content of conjugated dienes. The formation of conjugated dienes was analyzed to investigate the impact of emulsification as well as microencapsulation with $\mathrm{CP}$ and CP-HMP bilayer emulsions followed by spray drying on the oxidation of buriti oil (Table 3). The initial content of conjugated dienes in the buriti oil was high, which can be attributed to the thermal or chemical treatment during refining of the oil (Drusch et al., 2006). According to MoralesMedina et al. (2016), the homogenization of the emulsion can lead to oxygen inclusion. Furthermore, the shear forces as well as heating during spray drying can result in lipid oxidation. These effects were not observed in this study and the concentration of conjugated dienes remained constant after emulsification and spray drying processes. Similar result was reported by Drusch et al. (2006), who microencapsulated fish oil using noctenylsuccinate-derivatized starch and glucose syrup. They observed that the concentration of the conjugated dienes remained fairly constant during processing. One reason is that the determination of conjugated dienes is less sensitive than the analysis of hydroperoxides, on the other hand the buriti oil is stabilized through its antioxidative constituents limiting lipid oxidation during processing on a short time scale.

Table 3 Conjugated dienes of buriti oil, emulsions formulated with CP or CP-HMP, and microcapsules produced by spray drying at different temperatures

\begin{tabular}{lc}
\hline Sample & Conjugated dienes (mmol/kg oil) \\
\hline Buriti oil & $14.6 \pm 0.2$ \\
Emulsions & \\
$\mathrm{CP}$ & $14.8 \pm 0.5$ \\
$\mathrm{CP}-\mathrm{HMP}$ & $14.1 \pm 0.2$ \\
Microcapsules & \\
$\mathrm{CP} 180 / 70{ }^{\circ} \mathrm{C}$ & $14.6 \pm 1.0$ \\
$\mathrm{CP} 210 / 90^{\circ} \mathrm{C}$ & $13.9 \pm 0.9$ \\
$\mathrm{CP}-\mathrm{HMP} 180 / 70{ }^{\circ} \mathrm{C}$ & $14.3 \pm 1.0$ \\
$\mathrm{CP}-\mathrm{HMP} 210 / 90^{\circ} \mathrm{C}$ & $13.4 \pm 1.6$ \\
\hline
\end{tabular}

The oxidative stability of the microencapsulated oil on a time scale of six months is shown in Fig. 5. During six months of storage, a moderate increase of conjugated dienes (approx. $10 \mathrm{mmol} / \mathrm{kg}$ oil) was observed for all samples. Statistical analysis showed a significant, timedependent increase of the conjugated dienes. Post-hoc test revealed a lag time of 4 weeks 
(see Supplementary Material, Table S1). The stability of microcapsules in our study can be partially attributed to the high encapsulation efficiency, which ranged from 87 to $98 \%$. In general, the protection of oils against oxidation is closely related to the encapsulation efficiency (Özbek \& Ergönül, 2017). Aghbashlo et al. (2013) microencapsulated fish oil and correlated the encapsulation efficiency with the peroxide value during 4 weeks of storage. They observed that EE decreased while the peroxide value increased. According to the authors, the increase of peroxides can be related to the physical and chemical change of the capsule wall and the molecular diffusion of oil to the surface of the microcapsule, being easily oxidized. Besides that, the amount of permeated oxygen from the wall to the inside of the particle increases with storage time, resulting in higher lipid oxidation. Drusch et al. (2006) evaluated the stability of fish oil microcapsules stored at $20{ }^{\circ} \mathrm{C}$ and $33 \%$ relative humidity. They observed a fast increase in the amount of conjugated dienes, approx. 5 $\mathrm{mmol} / \mathrm{kg}$ oil in just 17 days after recrystallization of carbohydrates and thus physical changes in the matrix. Another factor that may have contributed to high oil stability is its composition. The buriti oil has a high level of phenolic compounds, which decreases its autoxidation, besides that contains carotenoids and tocopherols, which possess antioxidant activity (Cândido \& Silva, 2017; Choe \& Min, 2006).

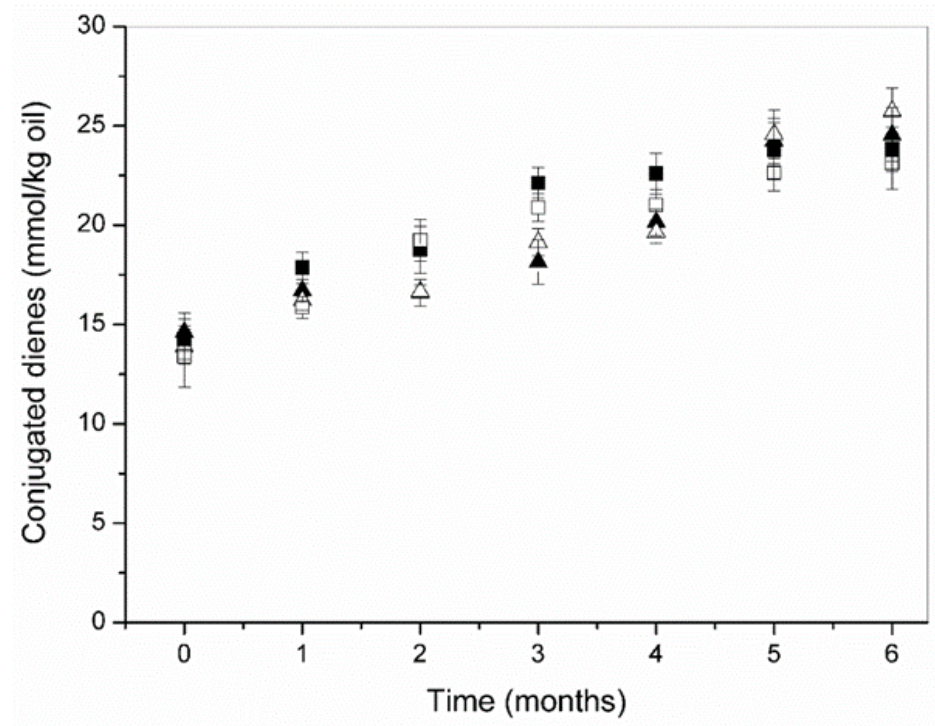

Fig. 5 Development of conjugated dienes content in microcapsules stabilized with $\mathbf{\Delta} C P 180 / 70{ }^{\circ} \mathrm{C}$, $\triangle C P 210 / 90{ }^{\circ} \mathrm{C}, \boldsymbol{C P}-H M P 180 / 70{ }^{\circ} \mathrm{C}$ and $\square \mathrm{CP}-H M P 210 / 90{ }^{\circ} \mathrm{C}$, produced by spray drying at different temperatures and storage at room temperature and $33 \%$ relative humidity.

The formulation, either with CP or CP-HMP, had no effect on the development of lipid oxidation. Serfert et al. (2013) also reported that there was no difference in the lipid oxidation between $\beta$-lactoglobulin and $\beta$-lactoglobulin-high methoxylated pectin microcapsules. This is in contradiction with Aberkane et al. (2014), who evaluated the oxidative stability of PUFArich oil stored at $20^{\circ} \mathrm{C}$ in different relative humidity ( $\mathrm{RH}$ from $11 \%$ to $75 \%$ ) for 8 weeks. The authors observed that lipid oxidation in spray dried emulsions formulated with pea proteinhigh methoxylated pectin was retarded compared to emulsions based on pea protein. However, since pectin may show trace metal-chelating activity depending on the distribution 
of free carboxylic groups, differences in stabilization may occur, which are not related to the physical structure of the interfacial film. Furthermore, spray drying at different temperatures had no effect on the lipid oxidation during 6 months. The spray drying air temperature affects properties such as water activity and moisture of the powders, the particle size, the rate of film formation around the droplets and the microcapsules wall, which may be porous or have cracks (Jafari et al., 2008; Özbek \& Ergönül, 2017). These characteristics influence the integrity and protection capacity of microcapsules, affecting their shelf life (Özbek \& Ergönül, 2017). Probably, the difference between $180 / 70{ }^{\circ} \mathrm{C}$ or $210 / 90{ }^{\circ} \mathrm{C}$ was not high enough to evaluate the effect of temperature on microcapsules stability.

\section{Conclusions}

In this work, chickpea protein and chickpea-pectin interfacial complexes were used to stabilize emulsions and microencapsulated the buriti oil by spray drying. The emulsions were spray dried at two temperatures, and the drying was performed once for each condition. CPHMP complexes resulted in stronger interfacial films with more interactions between the particles compared to $\mathrm{CP}$ alone. Probably the less interactions between protein particles in $\mathrm{CP}$ films resulted in droplets being more sensitive to disruption during spray drying. As a result, compared to $\mathrm{CP}$ alone reconstituted, spray-dried emulsions formulated with CP-HMP showed no changes in oil droplet size and spray dried powder had less surface oil, consequently leading to a higher encapsulation efficiency. During storage, the content of conjugated dienes increased for all samples. The use of microcapsules obtaind from either single layer or bilayer CP-HMP emulsions and the temperature of spray drying had no effect on the lipid oxidation. The present study clearly elaborates the potential of chickpea protein as a functional ingredient. In combination with pectin, buriti oil emulsions were successfully preserved by microencapsulation using an emulsification and spray drying process.

\section{Acknowledgments}

Poliana Moser is grateful to São Paulo Research Foundation - FAPESP (grant numbers 2017/05107-9, 2016/06204-5, and 2014/02910-7) for financial support. The authors gratefully acknowledge Dr. Ulrike Einhorn-Stoll and Dr. Hanna Kastner for the pectin and Christina Härter for the supporting analysis of conjugated dienes.

\section{Supplementary Material}

Table S1 Average values of the conjugated dienes formed during storage of microencapsulated buriti oil.

\begin{tabular}{lc}
\hline $\begin{array}{l}\text { Time } \\
\text { [week] }\end{array}$ & $\begin{array}{c}\text { Average value of conjugated dienes } \\
\text { [mmol/kg oil] }\end{array}$ \\
\hline 0 & $14.2 \pm 0.9^{\mathrm{a}}$ \\
4 & $16.6 \pm 1.0^{\mathrm{a}, \mathrm{b}}$ \\
8 & $17.8 \pm 1.4^{\mathrm{b}, \mathrm{c}}$ \\
12 & $20.1 \pm 2.1^{\mathrm{c}}$ \\
16 & $20.6 \pm 1.4^{\mathrm{c}, \mathrm{d}}$ \\
20 & $23.6 \pm 1.8^{\mathrm{d}, \mathrm{e}}$ \\
24 & $24.1 \pm 1.7^{\mathrm{d}, \mathrm{e}}$ \\
\hline Different letters in a column indicate significant differences at $\mathrm{p}<0.05$
\end{tabular}




\section{References}

Aberkane, L., Roudaut, G., \& Saurel, R. (2014). Encapsulation and Oxidative Stability of PUFA-Rich Oil Microencapsulated by Spray Drying Using Pea Protein and Pectin. Food and Bioprocess Technology, 7(5), 1505-1517. https://doi.org/10.1007/s11947013-1202-9

Aghbashlo, M., Mobli, H., Madadlou, A., \& Rafiee, S. (2013). Influence of Wall Material and Inlet Drying Air Temperature on the Microencapsulation of Fish Oil by Spray Drying. Food and Bioprocess Technology, 6(6), 1561-1569. https://doi.org/10.1007/s11947012-0796-7

AOAC. (2016). Official methods of analysis of AOAC International. AOAC International.

Bar-El Dadon, S., Pascual, C. Y., Eshel, D., Teper-Bamnolker, P., Paloma Ibáñez, M. D., \& Reifen, R. (2013). Vicilin and the basic subunit of legumin are putative chickpea allergens. Food Chemistry, 138, 13-18.

Böger, B. R., Georgetti, S. R., \& Kurozawa, L. E. (2018). Microencapsulation of Grape Seed Oil by Spray Drying. Food Science and Technology, 38(2), 263-270.

Bovi, G. G., Petrus, R. R., \& Pinho, S. C. (2017). Feasibility of incorporating buriti (Mauritia flexuosa L.) oil nanoemulsions in isotonic sports drink. International Journal of Food Science and Technology, 52(10), 2201-2209. https://doi.org/10.1111/ijfs.13499

Brückner-Gühmann, M., Heiden-Hecht, T., Sözer, N., \& Drusch, S. (2018). Foaming characteristics of oat protein and modification by partial hydrolysis. European Food Research and Technology, 244(12), 2095-2106. https://doi.org/10.1007/s00217-0183118-0

Can Karaca, A., Low, N. H., \& Nickerson, M. T. (2015). Potential use of plant proteins in the microencapsulation of lipophilic materials in foods. Trends in Food Science and Technology, 42(1), 5-12. https://doi.org/10.1016/j.tifs.2014.11.002

Cândido, T. L. N., \& Silva, M. R. (2017). Comparison of the physicochemical profiles of buriti from the Brazilian Cerrado and the Amazon region. Food Science and Technology, 37(suppl 1), 78-82. https://doi.org/10.1590/1678-457x.32516

Chang, Y., Alli, I., \& Molina, A. T. (2012). Isolation and Characterization of Chickpea ( Cicer arietinum L .) Seed Protein Fractions. Food and Bioprocess Technology, 618625. https://doi.org/10.1007/s11947-009-0303-y

Choe, E., \& Min, D. B. (2006). Mechanisms and factors for edible oil oxidation. Comprehensive Reviews in Food Science and Food Safety, 5(4), 169-186. https://doi.org/10.1111/j.1541-4337.2006.00009.x

Clemente, A., Vioque, J., Sánchez-Vioque, R., Pedroche, J., Bautista, J., \& Millán, F. (2000). Factors affecting the in vitro protein digestibility of chickpea albumins. Journal of the Science of Food and Agriculture, 80(1), 79-84. https://doi.org/10.1002/(SICI)1097-0010(20000101)80:1<79::AID-JSFA487>3.0.CO;24

Dagorn-Scaviner, C. Gueguen, J., \& Lefebvre, J. (1987). Emulsifying Properties of Pea Globulins as Related to Their Adsorption Behaviors. Journal of Food Science, 52, 335-341.

Dickinson, E. (2003). Hydrocolloids at interfaces and the influence on the properties of dispersed systems. Food Hydrocolloids, 17, 25. www.elsevier.com/locate/foodhyd

Dickinson, E. (2011). Mixed biopolymers at interfaces: Competitive adsorption and multilayer structures. Food Hydrocolloids, 25(8), 1966-1983. https://doi.org/10.1016/j.foodhyd.2010.12.001

Dickinson, E., \& Euston, S. R. (1991). Stability of food emulsions containing both protein and polysaccharide. In Eric Dickinson (Ed.), Food Polymers, Gels and Colloids (pp. 132-146). Woodhead Publishing.

Dickinson, E. (2009). Hydrocolloids as emulsifiers and emulsion stabilizers. Food 
Hydrocolloids, 23(6), 1473-1482. https://doi.org/10.1016/j.foodhyd.2008.08.005

Dickinson, Eric, \& Matsumura, Y. (1991). Time-dependent polymerization of $\beta$ lactoglobulin through disulphide bonds at the oil-water interface in emulsions. International Journal of Biological Macromolecules, 13(1), 26-30. https://doi.org/10.1016/0141-8130(91)90006-G

Drusch, S. (2007). Sugar beet pectin: A novel emulsifying wall component for microencapsulation of lipophilic food ingredients by spray-drying. Food Hydrocolloids, 21(7), 1223-1228. https://doi.org/10.1016/j.foodhyd.2006.08.007

Drusch, S. (2012). An industry perspective on the advantages and disadvantages of different fish oil delivery systems. In N. Garti \& D. J. McClements (Eds.), Encapsulation Technologies and Delivery Systems for Food Ingredients and Nutraceuticals (pp. 488-504). Woodhead Publishing.

Drusch, S., \& Berg, S. (2008). Extractable oil in microcapsules prepared by spray-drying: Localisation, determination and impact on oxidative stability. Food Chemistry, 109(1), 17-24. https://doi.org/10.1016/j.foodchem.2007.12.016

Drusch, S., \& Diekmann, S. (2015). Microencapsulation by Spray Drying. Handbook of Encapsulation and Controlled Release, 35-46. https://doi.org/10.1201/b19038-6

Drusch, S., \& Schwarz, K. (2006). Microencapsulation properties of two different types of n-octenylsuccinate-derivatised starch. European Food Research and Technology, 222, 155-164. https://doi.org/10.1007/s00217-005-0020-3

Drusch, Stephan, Serfert, Y., \& Schwarz, K. (2006). Microencapsulation of fish oil withnoctenylsuccinate-derivatised starch: Flow properties and oxidative stability. European Journal of Lipid Science and Technology, 108(6), 501-512. https://doi.org/10.1002/ejlt.200500312

Drusch, Stephan, Serfert, Y., Van Den Heuvel, A., \& Schwarz, K. (2006). Physicochemical characterization and oxidative stability of fish oil encapsulated in an amorphous matrix containing trehalose. Food Research International, 39(7), 807-815. https://doi.org/10.1016/j.foodres.2006.03.003

Freitas, M. L. F., Albano, K. M., \& Telis, V. R. N. (2017). Characterization of biopolymers and soy protein isolate-high-methoxyl pectin complex. Polímeros, 27(1), 62-67. https://doi.org/10.1590/0104-1428.2404

Freitas, M. L. F., Chisté, R. C., Polachini, T. C., Sardella, L. A. C. Z., Aranha, C. P. M., Ribeiro, A. P. B., \& Nicoletti, V. R. (2018). Quality characteristics and thermal behavior of buriti (<em>Mauritia flexuosa</em> L.) oil. Grasas y Aceites, 68(4), 220. https://doi.org/10.3989/gya.0557171

Ganzevles, R. A., Vliet, T. van, Cohen Stuart, M. A., \& de Jongh, H. H. J. (2007). Chapter 13. Manipulation of Adsorption Behaviour at Liquid Interfaces by Changing ProteinPolysaccharide Electrostatic Interactions. In Food Colloids (pp. 195-208). Royal Society of Chemistry. https://doi.org/10.1039/9781847557698-00195

Gehring, C. K., Gigliotti, J. C., Moritz, J. S., Tou, J. C., \& Jaczynski, J. (2011). Functional and nutritional characteristics of proteins and lipids recovered by isoelectric processing of fish by-products and low-value fish: A review. Food Chemistry, 124(2), 422-431. https://doi.org/10.1016/j.foodchem.2010.06.078

Gharsallaoui, A., Roudaut, G., Beney, L., Chambin, O., Voilley, A., \& Saurel, R. (2012). Properties of spray-dried food flavours microencapsulated with two-layered membranes: Roles of interfacial interactions and water. Food Chemistry, 132(4), 1713-1720. https://doi.org/10.1016/j.foodchem.2011.03.028

Gharsallaoui, A., Saurel, R., Chambin, O., Cases, E., Voilley, A., \& Cayot, P. (2010). Utilisation of pectin coating to enhance spray-dry stability of pea protein-stabilised oilin-water emulsions. Food Chemistry, 122(2), 447-454.

https://doi.org/10.1016/j.foodchem.2009.04.017 
Gharsallaoui, A., Yamauchi, K., Chambin, O., Cases, E., \& Saurel, R. (2010). Effect of high methoxyl pectin on pea protein in aqueous solution and at oil/water interface. Carbohydrate Polymers, 80(3), 817-827. https://doi.org/10.1016/j.carbpol.2009.12.038

International Dairy Federation. (1991). Anhydrous milk fat. Determination of peroxide value. In International IDF Standards.

Jafari, S. M., Assadpoor, E., He, Y., \& Bhandari, B. (2008). Encapsulation efficiency of food flavours and oils during spray drying. Drying Technology, 26(7), 816-835. https://doi.org/10.1080/07373930802135972

Jones, O. G., \& Mcclements, D. J. (2011). Recent progress in biopolymer nanoparticle and microparticle formation by heat-treating electrostatic protein - polysaccharide complexes. Advances in Colloid and Interface Science, 167(1-2), 49-62. https://doi.org/10.1016/j.cis.2010.10.006

Jourdain, L. S., Schmitt, C., Leser, M. E., Murray, B. S., \& Dickinson, E. (2009). Mixed layers of sodium caseinate + dextran sulfate: Influence of order of addition to oil-water interface. Langmuir, 25(17), 10026-10037. https://doi.org/10.1021/la900919w

Jung, J.-M., Gunes, D. Z., \& Mezzenga, R. (2010). Interfacial Activity and Interfacial Shear Rheology of Native $\beta$-Lactoglobulin Monomers and Their Heat-Induced Fibers. Langmuir: The ACS Journal of Surfaces and Colloids, 26(19), 15366-15375. https://doi.org/10.1021/la102721m

Karaca, A. C., Low, N., \& Nickerson, M. (2011). Emulsifying properties of chickpea, faba bean, lentil and pea proteins produced by isoelectric precipitation and salt extraction. Food Research International, 44(9), 2742-2750. https://doi.org/10.1016/j.foodres.2011.06.012

Karaca, A. C., Nickerson, M., \& Low, N. H. (2013). Microcapsule production employing chickpea or lentil protein isolates and maltodextrin: Physicochemical properties and oxidative protection of encapsulated flaxseed oil. Food Chemistry, 139(1-4), 448457. https://doi.org/10.1016/j.foodchem.2013.01.040

Klinkesorn, U., Sophanodora, P., Chinachoti, P., Decker, E. A., \& McClements, D. J. (2006). Characterization of spray-dried tuna oil emulsified in two-layered interfacial membranes prepared using electrostatic layer-by-layer deposition. Food Research International, 39(4), 449-457. https://doi.org/10.1016/j.foodres.2005.09.008

Krägel, J., \& Derkatch, S. R. (2010). Interfacial shear rheology. Current Opinion in Colloid and Interface Science, 15(4), 246-255. https://doi.org/10.1016/j.cocis.2010.02.001

Ladjal-Ettoumi, Y., Boudries, H., Chibane, M., \& Romero, A. (2016). Pea, Chickpea and Lentil Protein Isolates: Physicochemical Characterization and Emulsifying Properties. Food Biophysics, 11(1), 43-51. https://doi.org/10.1007/s11483-015-9411-6

Madadlou, A., Famelart, M. H., Pezennec, S., Rousseau, F., Floury, J., \& Dupont, D. (2020). Interfacial and (emulsion) gel rheology of hydrophobised whey proteins. International Dairy Journal, 100. https://doi.org/10.1016/j.idairyj.2019.104556

Madadlou, A., Floury, J., \& Dupont, D. (2018). Structural Assessment and Catalytic Oxidation Activity of Hydrophobized Whey Proteins. Journal of Agricultural and Food Chemistry, 66(45), 12025-12033. https://doi.org/10.1021/acs.jafc.8b02362

McClements, D. J. (2004). Protein-stabilized emulsions. Current Opinion in Colloid and Interface Science, 9(5), 305-313. https://doi.org/10.1016/j.cocis.2004.09.003

Morales-Medina, R., Tamm, F., Guadix, A. M., Guadix, E. M., \& Drusch, S. (2016). Functional and antioxidant properties of hydrolysates of sardine (S. pilchardus) and horse mackerel (T. mediterraneus) for the microencapsulation of fish oil by spraydrying. Food Chemistry, 194, 1208-1216. https://doi.org/10.1016/j.foodchem.2015.08.122

Moser, P., Telis, V. R. N., Andrade Neves, N., García-Romero, E., Gómez-Alonso, S., \& 
Hermosín-Gutiérrez, I. (2017). Storage stability of phenolic compounds in powdered BRS Violeta grape juice microencapsulated with protein and maltodextrin blends. Food Chemistry, 214, 308-318. https://doi.org/10.1016/j.foodchem.2016.07.081

Özbek, Z. A., \& Ergönül, P. G. (2017). A Review on Encapsulation of Oils. Celal Bayar Üniversitesi Fen Bilimleri Dergisi, 13(2), 293-309. https://doi.org/10.18466/cbayarfbe.313358

Papalamprou, E. M., Doxastakis, G. I., \& Kiosseoglou, V. (2010). Chickpea protein isolates obtained by wet extraction as emulsifying agents. Journal of the Science of Food and Agriculture, 90(2), 304-313. https://doi.org/10.1002/jsfa.3816

Piazza, L., Dürr-Auster, N., Gigli, J., Windhab, E. J., \& Fischer, P. (2009). Interfacial rheology of soy proteins - High methoxyl pectin films. Food Hydrocolloids, 23(8), 2125-2131. https://doi.org/10.1016/j.foodhyd.2009.05.012

Rosenberg, M., Rosenberg, Y., \& Zhang, J. (2018). Microencapsulation of a Model Oil in Wall System Consisting of Wheat Proteins Isolate (WHPI) and Lactose. Applied Sciences, 8(10), 1944. https://doi.org/10.3390/app8101944

Sanchéz-Vioque, J., Clemente, A., Vioque, J., Bautista, J., \& Millán, F. (1999). Protein isolates from chickpea ( Cicer arietinum L .): chemical composition, functional properties and protein characterization. Food Chemistry, 64, 237-243.

Serfert, Y., Schröder, J., Mescher, A., Laackmann, J., Rätzke, K., Shaikh, M. Q., Gaukel, V., Moritz, H. U., Schuchmann, H. P., Walzel, P., Drusch, S., \& Schwarz, K. (2013). Spray drying behaviour and functionality of emulsions with $\beta$-lactoglobulin/pectin interfacial complexes. Food Hydrocolloids, 31(2), 438-445. https://doi.org/10.1016/j.foodhyd.2012.11.037

Tamm, F., \& Drusch, S. (2017). Impact of enzymatic hydrolysis on the interfacial rheology of whey protein/pectin interfacial layers at the oil/water-interface. Food Hydrocolloids, 63, 8-18. https://doi.org/10.1016/j.foodhyd.2016.08.013

Tamm, F., Herbst, S., Brodkorb, A., \& Drusch, S. (2016). Functional properties of pea protein hydrolysates in emulsions and spray-dried microcapsules. Food Hydrocolloids, 58, 204-214. https://doi.org/10.1016/j.foodhyd.2016.02.032

Tamm, Frederic, Gies, K., Diekmann, S., Serfert, Y., Strunskus, T., Brodkorb, A., \& Drusch, S. (2015). Whey protein hydrolysates reduce autoxidation in microencapsulated long chain polyunsaturated fatty acids. European Journal of Lipid Science and Technology, 117(12), 1960-1970. https://doi.org/10.1002/ejlt.201400574

Ton, N. M. N., Tran, T. T. T., \& Le, V. V. M. (2016). Microencapsulation of rambutan seed oil by spray-drying using different protein preparations. International Food Research Journal, 23(1), 123-128.

Tonon, R. V., Grosso, C. R. F., \& Hubinger, M. D. (2011). Influence of emulsion composition and inlet air temperature on the microencapsulation of flaxseed oil by spray drying. Food Research International, 44(1), 282-289. https://doi.org/10.1016/j.foodres.2010.10.018

Walzel, P. (2010). Spraying and Atomizing of Liquids. In Ullmann's Encyclopedia of Industrial Chemistry. Wiley-VCH Verlag GmbH \& Co. KGaA.

Wang, R., Tian, Z., \& Chen, L. (2011). A novel process for microencapsulation of fish oil with barley protein. Food Research International, 44(9), 2735-2741. https://doi.org/10.1016/j.foodres.2011.06.013

Westergaard, V. (2004). Milk powder technology. In Evaporation and spray-drying (5th ed.). Niro A/S.

Xiong, T., Ye, X., Su, Y. T., Chen, X., Sun, H., Li, B., \& Chen, Y. (2018). Identification and quantification of proteins at adsorption layer of emulsion stabilized by pea protein isolates. Colloids and Surfaces B: Biointerfaces, 171(April), 1-9. https://doi.org/10.1016/j.colsurfb.2018.05.068 
